(C) [2008] IEEE. Reprinted, with permission, from Liu, Jingquan., Cankurtaran, Burak., Wuhrer, Richard., \& Cortie, Michael., 2008, 'Fabrication of double nano-cup assemblies and their anomalous plasmon absorption', COMMAD '08 Proceedings of the 2008 Conference on Optoelectronic and Microelectronic Materials and Devices, pp. 228-231. This material is posted here with permission of the IEEE. Such permission of the IEEE does not in any way imply IEEE endorsement of any of the University of Technology, Sydney's products or services. Internal or personal use of this material is permitted. However, permission to reprint/republish this material for advertising or promotional purposes or for creating new collective works for resale or redistribution must be obtained from the IEEE by writing to pubspermissions@ieee.org. By choosing to view this document, you agree to all provisions of the copyright laws protecting it. 


\title{
Fabrication of double nano-cup assemblies and their anomalous plasmon absorption
}

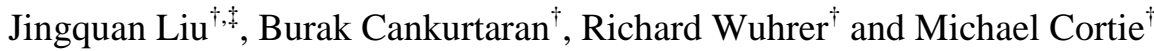 \\ †'Institute for Nanoscale Technology \\ University of Technology Sydney, Australia \\ Email: michael.cortie@uts.edu.au \\ now at University of New South Wales, Sydney Australia
}

\begin{abstract}
Double-cup assemblies of nanoscale gold semi-shells have been synthesized using a combination of thermal evaporation and chemical etching. The optical extinction of these structures peaked at $740 \mathrm{~nm}$, but there was also evidence of additional extinction maxima at 560, 940 and $1110 \mathrm{~nm}$. Numerical simulations of the optical properties revealed that the extinction was due mainly to scattering rather than to absorption In contrast, the extinction in simple single-shell nanocups was strongly absorptive in nature. Multiple plasmon resonances were identified in the double-cup structures, including an interesting quadrupole resonance in which oscillations of the inner and outer shells should operate $180^{\circ}$ out-of-phase.
\end{abstract}

Keywords- plasmon resonance, nanostructure, semi-shell, quadrupole, multipole

\section{INTRODUCTION}

A variety of precious metal nanoparticle shapes such as shells [1, 2], semi-shells [3], rods [4], caps [5, 6], cups [7, 8], rings [9, 10], rattles [11], triangles [12] and disks[13] have been synthesized. Potential applications of these particles include fields as disparate as medical treatment [14], functional glass windows $[15,16]$ and the sensing of analytes [17]. Some interesting structures formed by self-assembly of the individual particles have also been reported, for example gold platelets have been induced to form 3D structures [18, 19], gold shells can form asymmetrical dimers [20], spheres can assemble into close-packed solids [21, 22], and nanorods can form long chains [23-25].
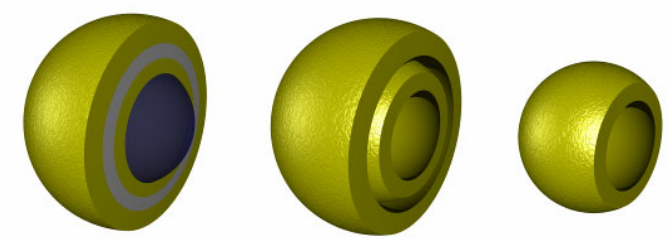

Figure 1. Schematic illustrations of structures examined in this paper, (left) composite particle showing polystyrene core, two layers of Au, and intermediate layer of $\mathrm{Al}$, (centre) same particle after removal of $\mathrm{Al}$ and core, (right) single-shell nanocup.

The idea of nanoscale shapes comprised of concentric spherical surfaces has also been mooted [2, 26-32] with the optical properties of such composite shapes being especially interesting. Here we describe a method to produce concentric double-cup, semi-shell, assemblies (Figure 1). The optical properties of these structures are investigated both experimentally and theoretically.

\section{EXPERIMENTAL}

\section{A. Fabrication of double cup assemblies}

Single shell nano-cups have been produced previously using wet chemistry [8] or physical vapor deposition (PVD) [17]. Here we have used a hybrid PVD/wet chemical method to produce the double-cup assemblies. First a template of polystyrene microspheres was spun-cast onto a glass slide. Next a layer each of gold, aluminum and then gold was sequentially thermally deposited at an angle of $50^{\circ}$ onto the substrate, which was simultaneously rotated. Each layer of metal was nominally $20 \mathrm{~nm}$ thick. Next the polymer cores were removed by $\mathrm{CH}_{2} \mathrm{Cl}_{2}$ and the intermediate aluminum layer by $2 \mathrm{M} \mathrm{HCl}$. The mouth of the cup, which is adjustable in size, can be varied by changing the angle of the metal source relative to the plane of the glass slide. Single cap particles were also produced, for comparison. The particles were then immobilized on a glass slide coated with aminopropyltrimethylsilane (APTMS) which forms a tether between glass and gold [33, 34] for measurement of their optical properties. The optical extinction of the nano-cup assemblies was measured experimentally after they were self-assembled on a glass substrate pre-coated with the APTMS. Scanning electron microscope images were taken in a Zeiss Supra 55VP using an in-lens secondary electron detector. Images were collected in high vacuum mode at $20 \mathrm{kV}$.

\section{B. Simulation of optical properties}

The optical properties of the structure were simulated with the discrete dipole approximation (DDA) using the DDSCAT code of Draine and Flatau $[35,36]$. The target structures were generated with custom-written software. The dipoles were of the order of $5 \mathrm{~nm}$ in size, sufficient in our experience to give peak positions and an approximation of peak shape, but not small enough to give an accurate value of extinction efficiencies. 


\section{RESULTS}
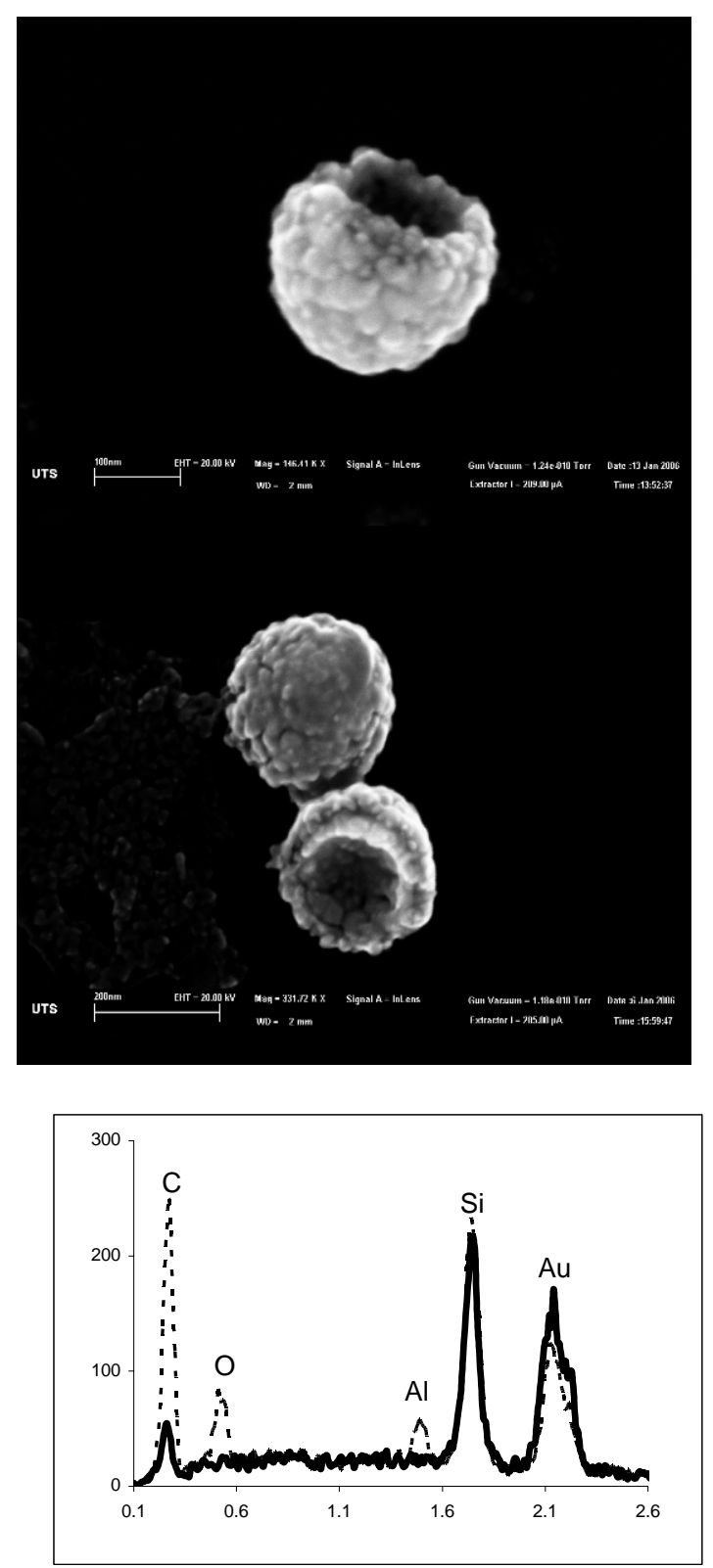

Figure 2. SEM micrograph of a) single nanocup assembly before removal of Al layer, b) pair of particles after removal of Al layer, c) energy dispersive Xray spectroscopy (EDS) spectrum of cup assembly before (dotted line) and after (solid line) removal of Al layer.

Figures $2 \mathrm{a}$ and $\mathrm{b}$ show examples of the cup assemblies. In some cases several assemblies were joined together, however the incidence of this was minimized by using a very dilute PSP solution. Such aggregates could also be readily separated out by precipitation. The dark line along the opening of the assembly corresponds to the removed layer of Al. Energy dispersive X-ray spectroscopy (EDS) was carried out in order to find out whether all the aluminum had been etched out. As shown in Figure 2c, the Al peak had indeed disappeared after the etching process. This analysis was performed several times on several particles.
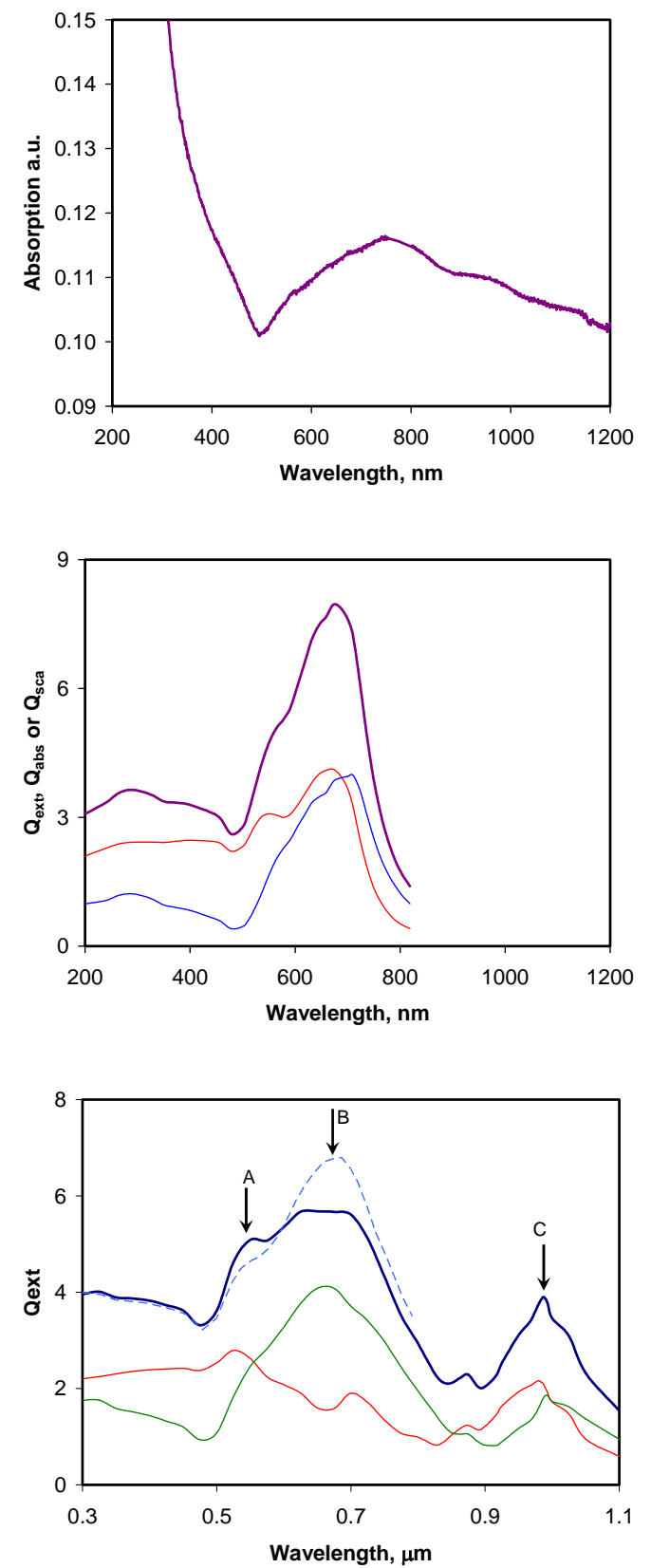

Figure 3. Optical absorption of nanocup assembly, (top) measured transmission spectrum of double semi-shells on a glass slide, (centre) orientationally-averaged extinction coefficients calculated for a simple gold semi-shell and (bottom) calculated extinction coefficients for double gold semi-shell (dashed: averaged over multiple orientation, solid: average of orientations shown in Figure 4). Note the strong absorption of UV by the glass slide in the experimental data, a feature which is necessarily lacking in the spectra calculated for the individual nanoparticles

Figure 3a gives the optical absorption of the double assemblies, as immobilized on the glass slide. The extinction peak was centered at $735 \mathrm{~nm}$. The calculated, orientationallyaveraged, extinction efficiencies of a single nano-cup, in vacuum, are shown in Figure 3b, and those for a double-cup in Figure $3 \mathrm{c}$. The extinction of the single cup is substantially due to two dipole resonances at 550 and $660 \mathrm{~nm}$, designated the $\alpha$ 
and the $\beta$ resonances and analogous to the transverse and longitudinal modes of other shapes [37]. Unlike the single cup, the double-cup exhibits significant extinction beyond $800 \mathrm{~nm}$, due evidently to at least one additional resonance, at $\mathrm{C}$. The calculated peak extinction of the assembly is at $675 \mathrm{~nm}$, somewhat lower than the measured $735 \mathrm{~nm}$. This discrepancy is most likely due to the red-shifting effect of the glass substrate in the experimental sample. However, it may also be due in part to the tapered nature of the deposits in real structures [38]. The illumination responsible for the extinction of Figure 3c can be broken into various components, Figure 4a, and the effect of each tested individually. When this is done it becomes evident that resonance $\mathrm{A}$ is due to component $\mathrm{J} 0=1$, and resonances $\mathrm{B}$ and $\mathrm{C}$ are due to component $\mathrm{J} 0=2$.

Furthermore, extinction in the single cup is due, in about equal proportions, to absorption and scattering. However, in these particles insertion of an additional semi-shell within the first has a marked effect on the nature of the optical extinction, with absorption becoming a vastly less significant phenomenon. The dipole resonance at position $\mathrm{C}$ of Figure $3 \mathrm{c}$ is quadrupole in nature, Figure $4 \mathrm{~b}$.
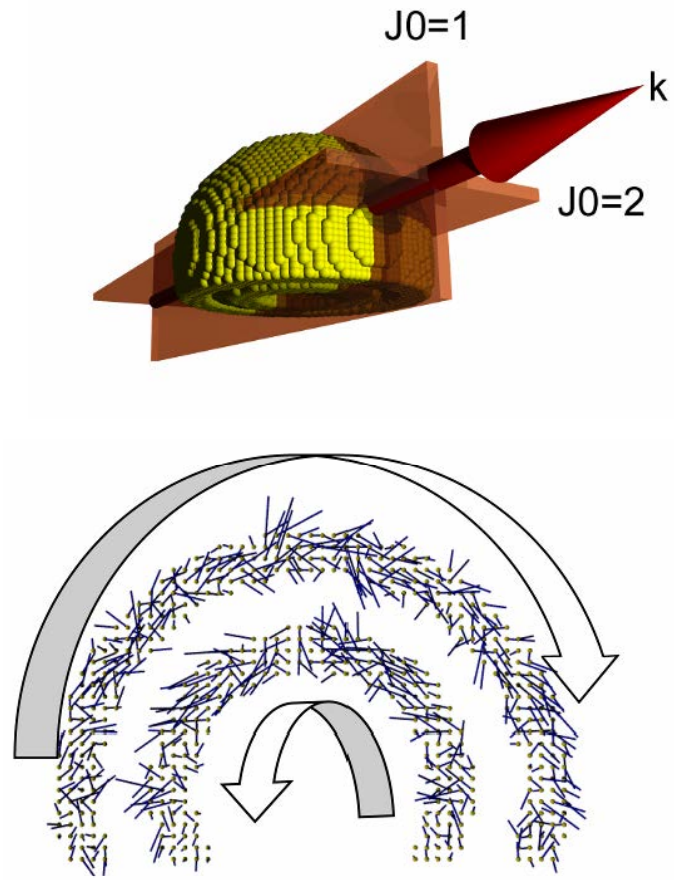

Figure 4. (a) The two distinct polarizations of light possible for this symmetry.(b) Quadrupole $\beta$ plasmon resonances produced in double-cup assembly at $975 \mathrm{~nm}$ by $\mathrm{J} 0=2$ polarization.

In conclusion, double-cup semi-shell assemblies can be produced by a templating process and offer some surprising and interesting optical properties. Not only do they exhibit anomalously strong scattering relative to absorption, but they also have a strong quadrupole plasmon resonance.

\section{ACKNOWLEDGMENT}

J. Liu thanks the Commonwealth Scientific and Industrial Research Organisation (CSIRO) of Australia for financial support.

\section{REFERENCES}

[1] H. S. Zhou, I. Honma, H. Komiyama, and J. W. Haus, "Controlled synthesis and quantum-size effect in gold-coated nanoparticles," Physical Review B, vol. 50, pp. 12052-12057, 1994.

[2] R. D. Averitt, D. Sarkar, and N. J. Halas, "Plasmon resonance shifts of Au-coated $\mathrm{Au}_{2} \mathrm{~S}$ nanoshells: Insight into multicomponent nanoparticle growth," Physical Review Letters, vol. 78, pp. 4217-4220, JUN 21997.

[3] J. Liu, A. I. Maaroof, L. Wieczorek, and M. B. Cortie, "Fabrication of hollow metal nanocaps and their red-shifted optical absorption spectra," Advanced Materials, vol. 17, pp. 1276-1281, 2005.

[4] J. Perez-Juste, I. Pastoriza-Santos, L. M. Liz-Marzan, and P. Mulvaney, "Gold nanorods: Synthesis, characterization and applications," Coordination Chemistry Reviews, vol. 249, pp. 1870-1901, 2005.

[5] J. C. Love, B. D. Gates, D. B. Wolfe, K. E. Paul, and G. M. Whitesides, "Fabrication and wetting properties of metallic half-shells with submicron diameters," Nano Letters, vol. 2, pp. 891-894, AUG 2002.

[6] H. Takei, " Surface-adsorbed polystyrene spheres as a template for nano-sized metal particle formation. Optical properties of nano-sized Au particle," J. Vac. Sci. Technol. B, vol. 17, pp. 1906-1911, 1999.

H. W. Deckman and J. H. Dunsmuir, "Applications of surface textures produced with natural lithography," Journal of Vacuum Science \& Technology B, vol. 1, pp. 1109-1112, 1983.

C. Charnay, A. Lee, S. Man, C. E. Moran, C. Radloff, R. K. Bradley, and N. J. Halas, "Reduced symmetry metallodielectric nanoparticles: chemical synthesis and plasmonic properties," Journal of Physical Chemistry B, vol. 107, pp. 7327-7333, 2003.

[9] F. Yan and W. A. Goedel, "Preparation of mesoscopic gold rings using particle imprinted templates," Nano Letters, vol. 4, pp. 1193-1196, 2004.

[10] J. A. Edgar, H. Zareie, A. Dowd, and M. Cortie, "Synthesis of hollow gold nanoparticles and rings using silver templates," in International Conference on Nanoscience and Nanotechnology (ICONN2008) Melbourne, Australia: ARC Nanotechnology Network, Canberra, 2008.

[11] M. Kim, K. Sohn, H. Bin Na, and T. Hyeon, "Synthesis of nanorattles composed of gold nanoparticles encapsulated in mesoporous carbon and polymer shells," Nano Letters, vol. 2, pp. 1383-1387, 2002. 
[12] S. S. Shankar, A. Rai, B. Ankamwar, A. Singh, A. Ahmad, and M. Sastry, "Biological synthesis of triangular gold nanoprisms," Nature Mater. , vol. 3, pp. 482-488, 2004.

[13] P. Hanarp, M. Kall, and D. S. Sutherland, "Optical properties of short range ordered arrays of nanometer gold disks prepared by colloidal lithography," Journal of Physical Chemistry B, vol. 107, pp. 57685772, JUN 192003.

[14] C. Loo, A. Lin, L. Hirsch, M. H. Lee, J. Barton, N. Halas, J. West, and R. Drezek, "Nanoshell-enabled photonics-based imaging and therapy of cancer," Technol. in Cancer Res. \& Treatment, vol. 3, pp. 3340, FEB 2004.

[15] X. Xu, M. Stevens, and M. B. Cortie, "In situ precipitation of gold nanoparticles onto glass for potential architectural applications," Chemistry of Materials, vol. 16, pp. 2259-2266, 2004.

[16] X. Xu, T. Gibbons, and M. B. Cortie, "Spectrallyselective gold nanorod coatings for window glass," Gold Bulletin, vol. 39, pp. 156-165, 2006.

[17] Y. Lu, G. L. Liu, J. Kim, Y. X. Mejia, and L. P. Lee, "Nanophotonic crescent moon structures with sharp edge for ultrasensitive biomolecular detection by local electromagnetic field enhancement effect," Nano Letters, vol. 5, pp. 119-124, JAN 2005.

[18] W. Huck, J. Tien, and G. M. Whitesides, "Threedimensional mesoscale self-assembly," J. Am. Chem.Soc., vol. 120, pp. 8267-8268, 1998.

[19] T. D. Clark, J. Tien, D. C. Duffy, K. E. Paul, and G. M. Whitesides, "Self-assembly of $10-* \mathrm{~m}$-sized objects into ordered three-dimensional arrays," J. Am. Chem. Soc., vol. 123, pp. 7677-7682, 2001.

[20] Y. Lu, H. Xiong, X. C. Jiang, Y. N. Xia, M. Prentiss, and G. M. Whitesides, "Asymmetric dimers can be formed by dewetting half-shells of gold deposited on the surfaces of spherical oxide colloids," Journal of the American Chemical Society, vol. 125, pp. 1272412725, OCT 222003.

[21] S. Sato, H. Yao, and K. Kimura, "Equilibrium growth of three-dimensional gold nanoparticle superlattices," Physica E, vol. 17, pp. 521-522, 2003.

[22] N. Harris, M. J. Ford, M. B. Cortie, and A. M. McDonagh, "Laser-induced assembly of gold nanoparticles into colloidal crystals," Nanotechnology, vol. 18, p. 365301, 2007.

[23] K. K. Caswell, J. N. Wilson, U. H. F. Bunz, and C. J. Murphy, "Preferential end-to-end assembly of gold nanorods by biotin-streptavidin connectors," Journal of American Chemistry Society, vol. 125, pp. 1391413915, 2003.

[24] K. G. Thomas, S. Barazzouk, B. I. Ipe, S. T. S. Joseph, and P. V. Kamat, "Uniaxial plasmon coupling through longitudinal self-assembly of gold nanorods," Journal of Physical Chemistry B, vol. 108, pp. 13066-13068, 2004.
[25] M. H. Zareie, X. D. Xu, and M. B. Cortie, "In situ organization of gold nanorods on mixed selfassembled-monolayer substrates," Small, vol. 3, pp. 139-145, Jan 2007.

[26] A. L. Aden and M. Kerker, "Scattering of electromagnetic waves from two concentric spheres," Journal of Applied Physics, vol. 22, pp. 1242-1246, 1951.

[27] A. E. Neeves and M. H. Birnboim, "Composite structures for the enhancement of nonlinear-optical susceptibility," J. Opt. Soc. Am. B vol. 6, pp. 787-796 1989.

[28] S. J. Oldenburg, R. D. Averitt, S. L. Westcott, and N. J. Halas, "Nanoengineering of optical resonances," Chem. Phys. Lett., vol. 288, pp. 243-247, 1998.

[29] R. Baer, D. Neuhauser, and S. Weiss, Nano Letters, vol. 4, pp. 85-88, 2004.

[30] E. Prodan and P. Nordlander, "Plasmon hybridization in spherical nanoparticles," Journal of Chemical Physics, vol. 120, pp. 5444-5454, 2004.

[31] Y. Sun, B. Wiley, Z.-Y. Li, and Y. Xia, "Synthesis and optical properties of nanorattles and multiplewalled nanoshells/nanotubes made of metal alloys," Journal of the American Chemical Society, vol. 126, pp. 9399-9406, 2004.

[32] E. Prodan, C. Radloff, N. J. Halas, and P. Nordlander, "A hybridization model for the plasmon response of complex nanostructures," Science, vol. 302, pp. 419422, 2003.

[33] S. L. Westcott, S. J. Oldenburg, T. R. Lee, and N. J. Halas, "Formation and adsorption of clusters of gold nanoparticles onto functionalized silica nanoparticle surfaces," Langmuir, vol. 14, pp. 5396-5401, 1998.

[34] Y. Liu, V. N. Khabashesku, and N. J. Halas, Journal of the American Chemical Society, vol. 127, pp. 3712-3713, 2005.

[35] B. T. Draine and P. J. Flatau, "Discrete-dipole approximation for scattering calculations," J. Opt. Soc. Am. A, vol. 11, pp. 1491-1499, 1994.

[36] B. T. Draine and P. J. Flatau, "User Guide for the Discrete Dipole Approximation Code DDSCAT 6.1," 2004.

[37] M. B. Cortie and M. J. Ford, "Plasmon-induced current loops in gold semi-shells," Nanotechnology, vol. 18, p. 235704, 2007.

[38] A. I. Maaroof, M. B. Cortie, N. Harris, and L. Wieczorek, "Mie and Bragg plasmons in subwavelength silver semi-shells," Small, p. in press, 2008. 